\title{
Nuclear localization of phosphorylated ERK1 and ERK2 as markers for the progression of ovarian cancer
}

\author{
ABRAHAM AMSTERDAM ${ }^{1}$, ELIAS SHEZEN ${ }^{2}$, CALANIT RAANAN $^{3}$, LETIZIA SCHREIBER $^{4}$, \\ DIANA PRUS ${ }^{5}$, YASMIN SLILAT ${ }^{1}$, ALON BEN-ARIE $^{6}$ and RONY SEGER ${ }^{7}$
}

\begin{abstract}
Departments of ${ }^{1}$ Molecular Cell Biology, ${ }^{2}$ Immunology, ${ }^{3}$ Biological Services, The Weizmann Institute of Science, Rehovot 76100, Israel; ${ }^{4}$ Wolfson Hospital, Holon 58100, Israel; ${ }^{5}$ Department of Pathology, University Hospital, Hadassah Ein Kerem, Jerusalem 911210; ${ }^{6}$ Kaplan Medical Center, Rehovot 76100; ${ }^{7}$ Department of

Biological Regulation, The Weizmann Institute of Science, Rehovot 76100, Israel
\end{abstract}

Received April 15, 2011; Accepted May 18, 2011

DOI: 10.3892/ijo.2011.1090

\begin{abstract}
We examined the possibility that the localization of phosphorylated ERK1 and ERK2 (pERK1/2) can serve as a marker for the development of benign and borderline tumors as well as carcinoma of the ovary by an immunohistochemical method on ovarian paraffin sections, obtained from women aged 41-83 years. In normal tissue, $28.3 \%$ of nuclei were labeled, mainly confined to the epithelial cells at the surface of the ovary. In benign serous tumors, the label rose to $55.0 \%$, while the intensity of the staining was weak. In contrast, in borderline serous tumors and in ovarian serous carcinoma (stage II) $52.1 \%$ and $70.3 \%$ of nuclei, respectively, were labeled with a high intensity. In mucinous benign tumors, the number of labeled nuclei was as in the control, but in addition, $49.4 \%$ of the cells demonstrated high concentration of pERK1/2 in aggregated form that was evident in the cytoplasm of the cells. In the mucinous and endometrioid ovarian carcinomas (stage II) very intensive labeling was found in $60 \%$ and $77.3 \%$ of cells, respectively. It is, therefore, suggested that since nuclear $p E R K 1 / 2$ can be mitogenic, it can serve as a reliable marker for the progression of ovarian cancer. Interestingly, the intense labeling of pERK1/2 was mainly confined to the peripheral areas of ovarian endometrioid carcinoma (stage II). In addition, all tumor cells in this class of cancer were positively stained with mutated p53. It seems, therefore, that immunohistochemical staining of normal and ovarian tumor cells with anti-pERK1/2 is a reliable marker for early detection of the cancer, which may assist in the early diagnosis and prognosis of this lethal disease.
\end{abstract}

Correspondence to: Dr Abraham Amsterdam, Department of Molecular Cell Biology, The Weizmann Institute of Science, Rehovot 76100, Israel

E-mail: abraham.amsterdam@weizmann.ac.il

Key words: ovarian cancer, MAPK, pERK1/2, p53

\section{Introduction}

Epithelial ovarian cancer is the most lethal gynecological cancers in women and is frequently developed in postmenopausal women (reviewed in refs. 1-14). It is subdivided according to the pathological appearance and molecular markers to four groups: serous-adenocarcinomas comprises $80 \%$ of the cancer and the rest are mucinous carcinomas, endometrioid carcinomas and clear cell carcinomas (reviewed in refs. 1-15). Earlier it was reported that about $12-13 \%$ of total ovarian carcinomas are mucinous carcinomas, but recently, using new molecular markers, it was considered as only $2-3 \%$ of total ovarian carcinomas (16). Low-grade serous carcinomas are characterized by frequent mutation of KRAS, BRAF and ERBB2 genes, but lack of p53 mutations. In contrast, the vast majority of high-grade serous carcinomas express the mutated p53, but lack mutations of KRAS, BRAF and ERBB2 (3,17-23). Immunohistochemical techniques revealed staining of p53, p16 and Ki67 in high-grade carcinomas (3,17). Distinction between the low-grade and the high-grade serous carcinomas may suggest that the low-grade ovarian carcinomas are not the origin of the high-grade ovarian serous carcinomas $(3,17)$.

The prognosis of serous ovarian carcinomas was found to be of 40.8-month, while the prognosis of mucinous ovarian carcinomas was found to be extremely poor and was only 14.6 months. The prognosis of clear cell carcinomas and endometrioid carcinomas was 21.3 and 50.9 months, respectively (reviewed in refs. 1-15). Primary mucinous ovarian carcinomas have a sign frequently of higher prevalence of KRAS mutations and lower frequency of BRCA and p53 abnormalities $(16,22,24)$. The worse prognosis of mucinous ovarian cancer arises probably from the fact that this type of cancer is largely platinum and taxane resistance (reviewed in refs. 16,25). Clear cell carcinoma is the second most common type of ovarian epithelial cancer representing 5\% of ovarian carcinomas (26). It is characterized by its association with endometriosis and frequent mutations of ARID1 and PIKM3CA (reviewed in refs. $16,26)$.

In serous ovarian cancer as well as in other types of ovarian cancers, receptors to EGF and EGF like factors as well as the appropriate ligands, are clearly expressed (reviewed in refs. 
27-34). The most remarkable finding is a significant increase of the level of HER2 which correlates also with relatively poor prognosis (40.9 months) of serous ovarian type of cancer (reviewed in ref. 17). In addition, VEGF is also expressed in serous ovarian carcinoma and it is probably related to mitotic activity of the cancerous tissue (35). It should be noted that expression of mutated p53 and HER-2 is frequently expressed in all types of ovarian cancer $(2,17-19,22,31,35,39)$ Another parameter that probably increases the aggressiveness of ovarian cancer in general is the de novo formation and secretion of heparanase which degrade the extracellular matrix (36-38), and thus may facilitate the migration of the cancer cells through the walls of the blood vessels.

The extracellular signal-regulated kinase 1 and 2 (ERK1/2) is a central intracellular signaling pathways that plays a key role in the induction of proliferation, differentiation and apoptosis (reviewed in refs. 39,40). In quiescent cells, ERK1/2 are retained in the cytoplasm due to their interaction with various anchoring proteins, including their upstream regulators MEK1/2. Following stimulation, ERK1/2 are phosphorylated on threonine and tyrosine residues (pERK1/2), which induce their activation and dissociation from most of the cytoplasmic anchors. This dissociation is necessary for nuclear translocation of pERK1/2, which is achieved by a specific nuclear translocation signal (NTS) within the kinase domain of the proteins $(39,41,42)$. Stimulation and nuclear localization of pERK $1 / 2$ is required for diverse cellular functions such as in neurite outgrowth in PC12 cells (43) and the transformation of fibroblasts (44). In ovarian carcinomas, in general, there is a potential that EGF like factors will bind to a family of EGF receptors on the target cell membrane (31-34). This binding activates the receptor, which in turn phosphorylates and activates ERK1/2, which induce their nuclear localization $(39,40-42,45)$. However, there is no follow-up reports on the nuclear localization of pERK1/2 in tissues of ovarian cancer or in any other cancerous tissue. In the present study we demonstrate for the first time nuclear labeling of pERK1/2 in normal ovarian tissues and benign and borderline tumors, and in carcinomas of the ovary. Our findings suggest that the nuclear pERK1/2 may be an important early biomarker for the development of ovarian cancer.

\section{Materials and methods}

Materials. Monoclonal antibodies to p53 (clone 421) were kindly donated by Professor M. Oren of our Institute. Antibodies to pERK1/2 were mouse monoclonal antibodies that recognize only the phosphorytated form of the ERK's and not the non-phosphorylated form (40) using a dilution of 1:200 (Sigma-Aldrich M8159, St. Louis, MO, USA). Second specific antibodies conjugated to HRP were from N-Histofine, Japan.

Procedures. Localization of pERK1/2 was performed by the indirect immunostaining method of ovarian sections, formaldehyde fixed, and paraffin-embedded specimens $(3,17,33,36)$, obtained from women at the age of 41-79 through several hospitals in Israel. For control, sections of normal ovaries were obtained from women aged 41-73 years. Specimens of paraffin sections were obtained from 8 normal ovaries and 5-7 ovaries of benign, borderline and carcinomas of each group. As for endometrioid ovarian cancer, we studied only 2 carcinoma specimens. The carcinomas were at stage II. Permissions for the research were obtained from Helsinki Committees of each hospital: Kaplan Medical Center, Rehovot, Israel, Hadassah Hospital, Ein Kerem, Jerusalem, Israel and the Wolfson Hospital, Holon, Israel. Staining of sections with anti-p53 were performed using specific antibodies, followed by staining with secondary specific antibodies conjugated to peroxidase against the primary antibodies.

Microscopic examination. Immunostained sections and parallel sections stained with heamatoxylin and eosin were observed in Olympus or Nikon microscopes using x10-x1000 magnification. For scoring the number of labeled cells and nuclei in normal and different stages of the ovarian tumor development, pictures were taken at x1000 magnification. Six to twelve different areas of stained slides of each different stage of ovarian tumor development (and controls of normal ovaries) were photographed and the number of labeled nuclei and total nuclei were scored, calculating the percentage of labeled nuclei in each photograph, and the mean value \pm SD of all fields were calculated as well. At each stage of the ovarian tumor development (and normal tissue) total of about 750 nuclei were scored. It should be noted that at normal ovaries pictures were taken to show both the stroma and the epithelial cells, while in ovaries containing the tumors pictures were taken in the main bulk of the tumors.

Statistics. Statistic evaluation of the different percentage of labeled nuclei among the different stages of ovarian tumors development was performed, including control of normal ovary. Analysis of variance (ANOVA) followed by multiple comparison tests or Student's t-test as appropriate was performed. Calculations were performed using SPSS software (Student's t-test, version II, Chicago, IL, USA). Values of $\mathrm{P}<0.05$ were considered statistically significant.

\section{Results}

Normal ovary. In a normal ovary, only $28.3 \pm 11.3 \%$ SD of the nuclei were labeled with anti-pERK1/2 (Figs. 1 and 2A). The label was located both in the cytoplasm and nuclei and was mainly confined to the epithelial cells in the surface of the ovary (Figs. 1 and 2A). The stromal cells were mainly free of labeling, although some stromal cell nuclei were also weakly stained. However, it should be noted that in some normal ovaries (3 of 8 ) which were classified as normal, according to morphological criteria, there was more intensive labeling of pERK $1 / 2$ even in stromal cells, often in the ovarian periphery, which would suggest that these ovaries may represent higher potential to develop ovarian cancer (data not shown). Therefore, these three ovaries were not scored as normal ovaries.

Ovarian serous tumors. In benign serous tumors (Fig. 2B), the label was still low and was located in the nuclei of the cells $(55.0 \pm 14.0 \% \mathrm{SD})$, while the percentage of labeled nuclei was significantly elevated above the control $\mathrm{P}<0.006$ (Figs. 1 and 2B). In serous borderline tumors 52.1 $\pm 5.7 \mathrm{SD}$ of nuclei were labeled, significantly above the control $(\mathrm{P}<0.0002)$ while the intensity of labeling was much higher than in normal ovary (Figs. 1, 2C and D) compared to normal ovary and benign 


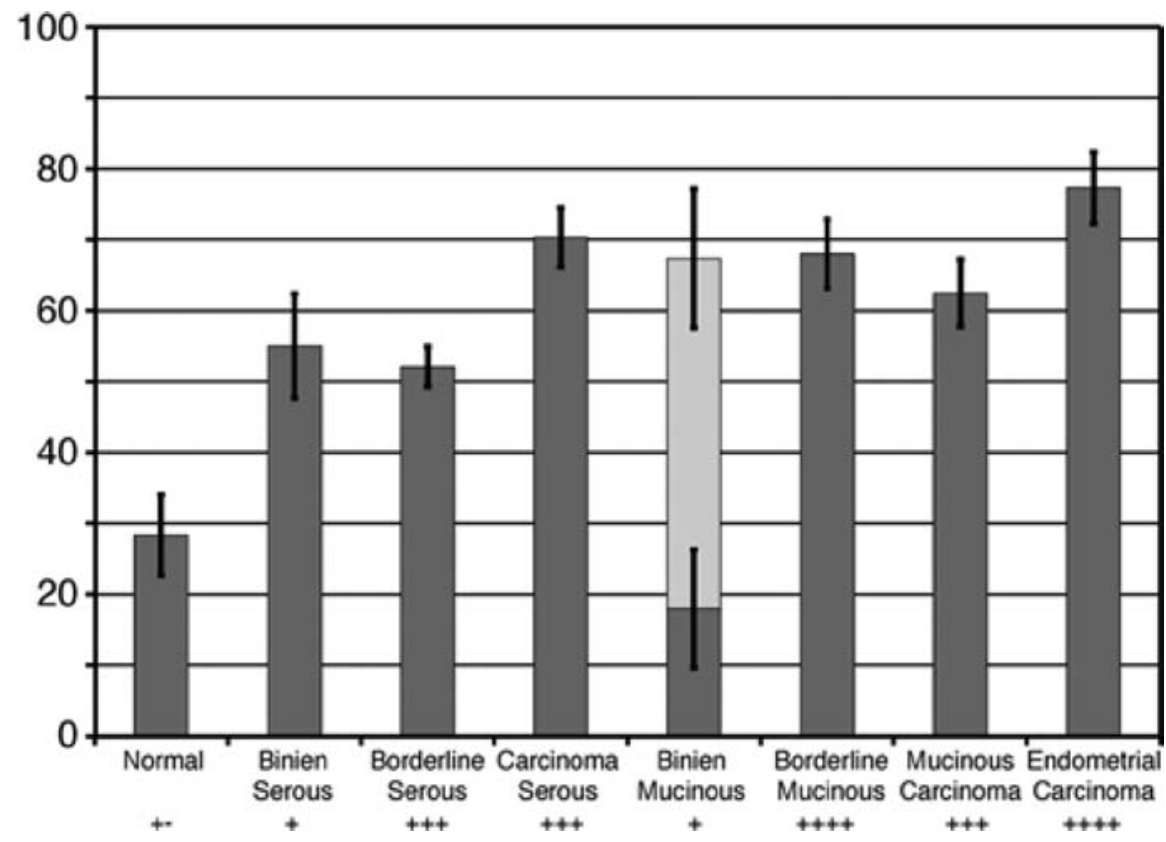

Figure 1. Statistics of percentage-labeled nuclei with pERK1/2 in normal ovary compared to tumor tissue. The gray bar represents benign mucinous tumor cells, where labeling is evident in the cytoplasm, while the nuclei remained unstained +-, resembles the intensity of staining. The difference between labeled nuclei in normal ovary (NO) and benign serous tumor is $\mathrm{P}<0.006$, between $\mathrm{NO}$ and borderline serous tumor is $\mathrm{P}<0.0002$ and between $\mathrm{NO}$ and serous carcinomas is $\mathrm{P}<0.00005$. However there is no significant difference between labeled nuclei between $\mathrm{NO}$ and benign mucinous tumors $\mathrm{P}=0.2$. There is a significant difference between NO and borderline mucinous tumors $\mathrm{P}<0.0007$ and mucinous carcinomas $\mathrm{P}<0.0002$. Significant difference is also evident between NO and endometrioid carcinoma, $\mathrm{P}<0.0002$. There are also significant differences between benign serous tumors and serous carcinomas $\mathrm{P}<0.05$ as well as between borderline serous tumors and serous carcinomas $\mathrm{P}<0.001$. The same significant difference between $\mathrm{NO}$ and endmetrial cancer exists $(\mathrm{P}<0.00002)$.

tumors. It should be noted that two different cell populations of borderline tumors were evident in different patients. The first was characterized by tightly packed small cells and small nuclei (Fig. 2C), and the second by more loosely packed cells and larger nuclei (Fig. 2D). In serous adenocarcinoma there was high labeling in the nuclei of the tumors, while in stromal cells low labeling was sometimes evident (Fig. 2E). High magnification images at the center of the carcinomas revealed 70.3 \pm 8.3 SD, of nuclear staining (Figs. 1 and 3). The percentage of labeled cells was significantly higher than in benign tumors $(\mathrm{P}<0.05)$ and in borderline tumors $\mathrm{P}<0002$ (Figs. 1 and 3). Also, in the carcinomas there were two different patterns of staining of the carcinomas. The first comprised round large nuclei with clear staining both in the cytoplasm and the nuclei (Fig. 3A) while the second image comprised stained nuclei irregular in shape, while the cytoplasm was weakly stained. Some of the nuclei remained unstained (Fig. 3B).

Mucinous tumors. Morphologically it was hard to distinguish between benign and borderline mucinous tumors. However, staining of tumor sections with anti-pERK1/2 antibodies helped to distinguish between benign and borderline mucinous tumors.

In benign tumors only $17 \pm 1.1 \% \mathrm{SD}$ of the nuclei were labeled. This figure was not significantly different as compared to control ovaries (Figs. 1 and $4 \mathrm{~A})(\mathrm{P}=0.24)$. It should be noted that the label of pERK1/2 was confined to clusters of 2-3 cells in the mucinous cell layers and was evident both in the nuclei of these clustered cells and in a weak staining at the circumference of these cells, while most of the cells remained unlabeled (Fig. 4A). However, local high concentration of $\mathrm{pERK} 1 / 2$ was found in most patients in cytoplasmic inclusions of additional $49 \pm 16.7 \%$ SD of cells (Figs. 1 and 4B). In those cells the nuclei were still free of labeling. These images may represent initial development of mucinous ovarian tumors. In borderline tumors extremely high labeling was found both in the cytoplasm and the nuclei of the cells (68+9\% SD) (Figs. 1, 4C and D). Interestingly, the labeling in the cytoplasm appeared sometime in small numerous aggregates (Fig. 4D), and high labeling could be observed in stromal cells adjacent to the tumor cells (Fig. 4C and D). In mucinous carcinomas high labeling was confined to the nuclei of cells $62.5 \pm 9.5 \%$ SD (Figs. 1, 4E and F) as were scored in high magnification at the central core of the carcinoma (Fig. 4F).

Endometrioid ovarian carcinomas. Since this type of tumor is relatively rare $(5 \%)(7,9)$, we found only a couple of cases of ovarian endometrioid carcinoma. We could not identify benign tumors and borderline tumors. Staining with antipERK1/2 antibodies of the carcinomas yielded heavy labeling of tumor cells. pERK1/2 was mainly located in the periphery of the tumors, leaving the center of the tumor unstained (Fig. 5A and B). When analyzed, the labeled areas at x1000 magnification (Fig. 5C), it was found that $77 \pm 10.1 \%$ SD of the cells showed extremely high labeling both in the nuclei and the cytoplasm (Figs. 1 and 5C). Interestingly, when stained to p53 all nuclei of the carcinoma cells were heavily labeled (Fig. 5D). It should be noted that also some stromal cell nuclei adjacent to the tumors were also labeled with pERK1/2 (Fig. 5A). The tumor cells could be distinguished from the stromal cancer cells by the small size of oval appearance of the nuclei. 

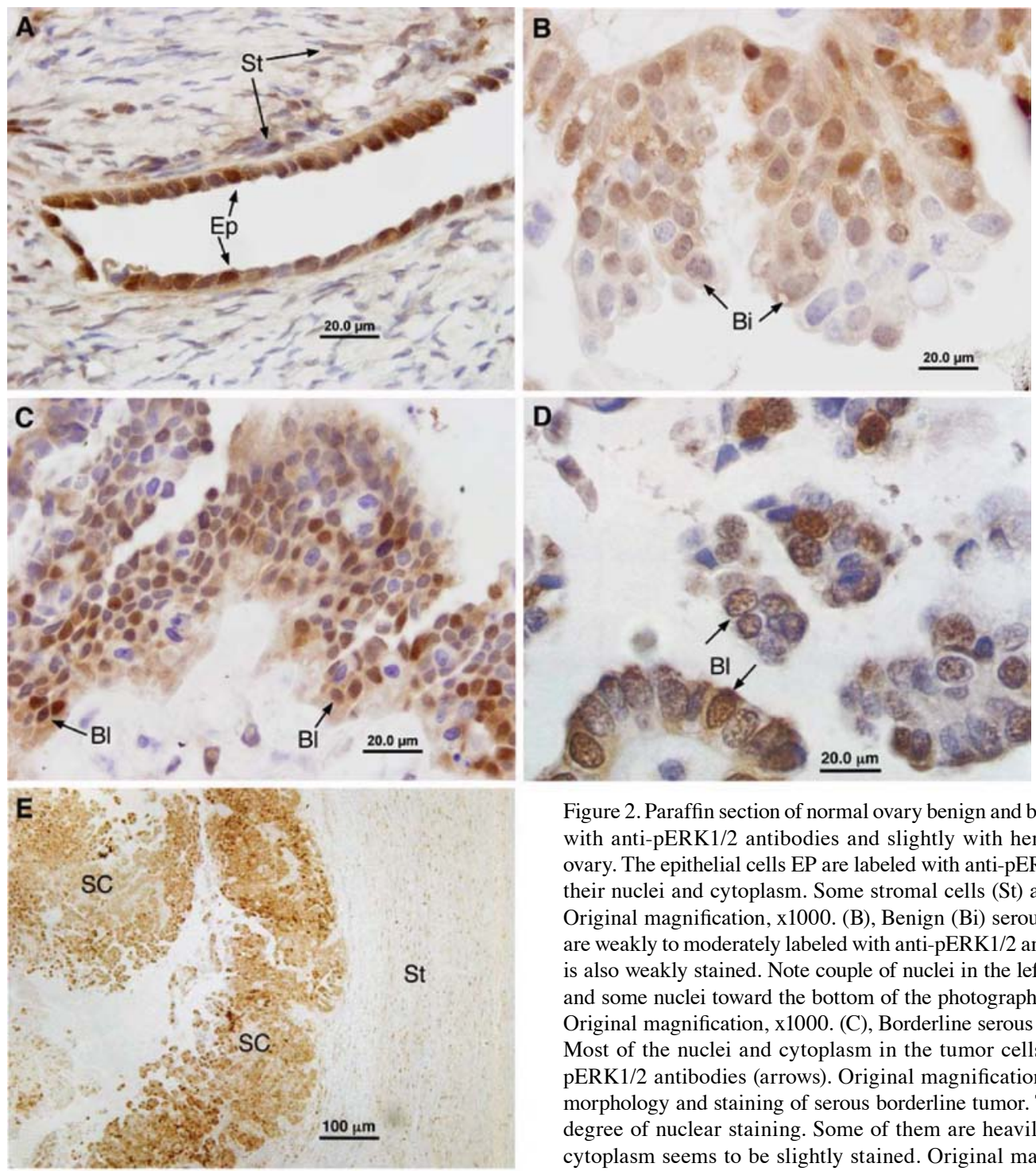

Figure 2. Paraffin section of normal ovary benign and borderline tumors stained with anti-pERK1/2 antibodies and slightly with hematoxylin. (A), Normal ovary. The epithelial cells EP are labeled with anti-pERK1/2 antibodies both in their nuclei and cytoplasm. Some stromal cells (St) are also weakly stained. Original magnification, x1000. (B), Benign (Bi) serous ovarian tumor. Nuclei are weakly to moderately labeled with anti-pERK1/2 antibodies. The cytoplasm is also weakly stained. Note couple of nuclei in the left side of the photograph and some nuclei toward the bottom of the photograph that remain unlabelled. Original magnification, x1000. (C), Borderline serous ovarian carcinoma (Bl). Most of the nuclei and cytoplasm in the tumor cells are labeled with antipERK1/2 antibodies (arrows). Original magnification, x1000. (D), Different morphology and staining of serous borderline tumor. There is variation in the degree of nuclear staining. Some of them are heavily stained (arrows). The cytoplasm seems to be slightly stained. Original magnification, x1000. (E), Ovarian serous adenocarcinoma (SC). Nuclei of the tumor are clearly labeled. Some nuclei of stromal cells are also slightly labeled. Original magnification, $\mathrm{x} 100$

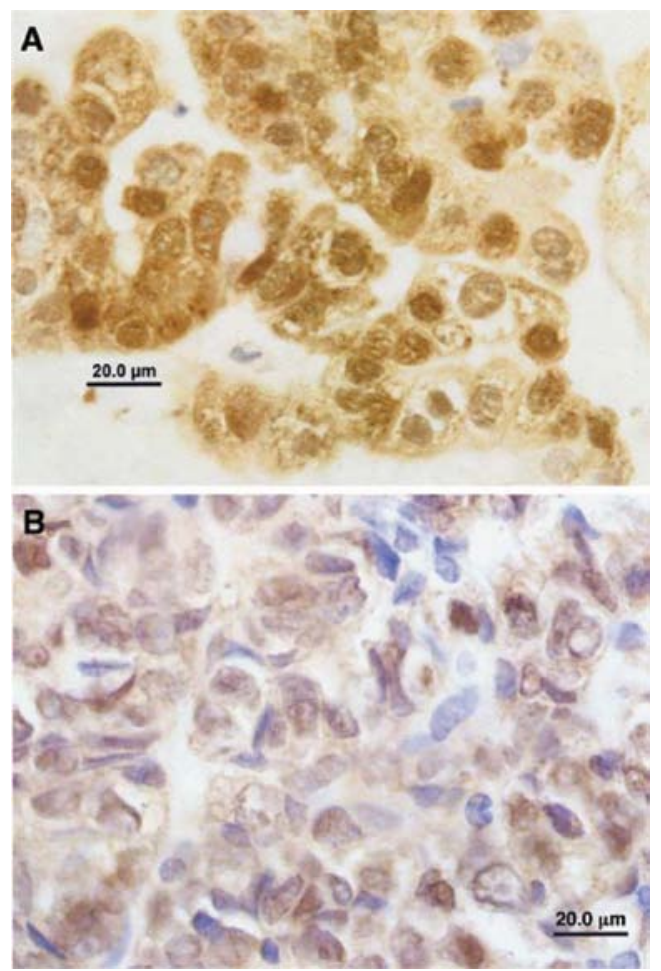

Figure 3. Serous ovarian carcinoma (SC). (A), High magnification following staining with anti-pERK1/2. Nuclei and cytoplasm are clearly labeled. The nuclei show round appearance. Original magnification, x1000. (B), Another morphological appearance of serous ovarian carcinoma most of nuclei irregular in shape are labelled with anti-pERK1/2 antibodies while some remained unstained. Original magnification, $\mathrm{x} 1000$.

\section{Discussion}

Our results indicate that the appearance of nuclear pERK1/2 correlates with the development of ovarian cancer. It was earlier demonstrated that in cancer cell lines pERK1/2 can enter the nucleus $(2,39,41,42,46)$, but we demonstrate here for the first time a correlation between increase in number and intensity of pERK1/2 labeled nuclei with progression of the ovarian cancer. The translocation of pERK1/2 into the nucleus is probably triggered by the de novo synthesis of EGF-like factors such as HB-EGF, amphiregulin, epiregulin and TGF $\alpha$ after shedded to the extracellular space, cleaved by the metalloproteins ADAM-17 and possibly ADAMTS1 $(29,47)$, and bind to the EGF receptor, which become phosphorylated (45). 

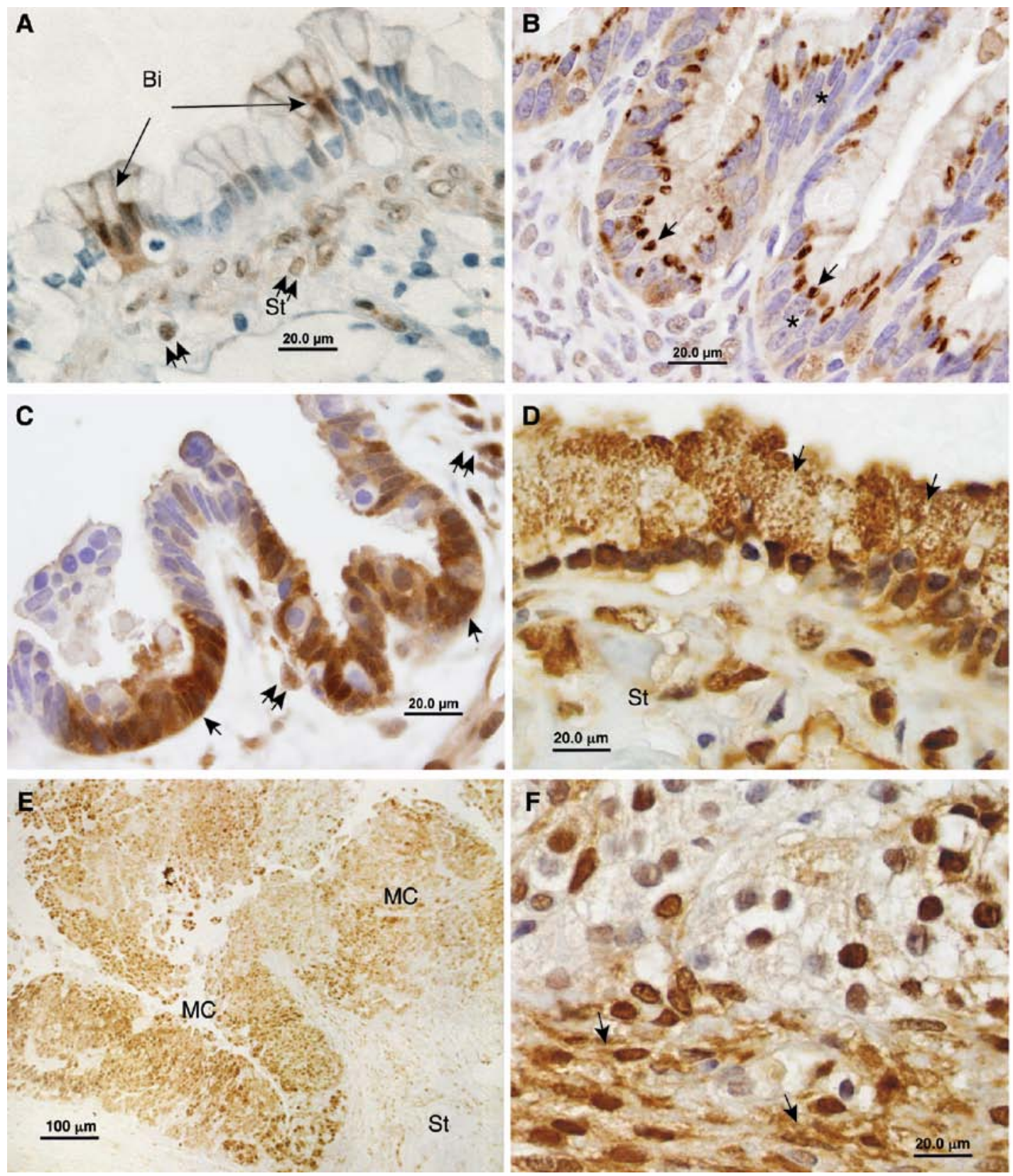

Figure 4. Mucinous benign and borderline tumors as well as mucinous carcinoma. (A), Some nuclei and cytoplasm are weakly stained in clustered cells of the benign tumor (Bi). Some nuclei in the stroma (St) adjacent to the tumor cells are also stained (double arrows). Original magnification, $\mathrm{x} 1000$. (B), Another image of ovarian mucinous benign tumor. Cells are clearly stained with anti-pERK. The stain is concentrated in distinct cytoplasm inclusions (arrows) leaving the nuclei free of labeling with anti-pERK1/2 antibodies (asteriscs). Original magnification, x1000. (C), Borderline mucinous ovarian tumor stained with anti-pERK1/2 antibodies. Clusters of cells are clearly heavily labeled both in the cytoplasm and nuclei (arrows). Some cell nuclei in the stroma are also clearly stained (double arrows). Original magnification, x1000. (D), Another pattern of staining of ovarian mucinous borderline tumors with anti-pERK1/2 antibodies. Cell nuclei are heavily labeled both in the tumor and in the stroma (St). The cytoplasm of tumor cells is loaded with small aggregates of pERK1/2 antibodies (arrows). Original magnification, x1000. (E), Low magnification of mucinous ovarian cancer (MC) following staining with anti-pERK1/2 antibodies. Some stromal cell nuclei are also weakly labeled. Original magnification, x100.(F), Mucinous ovarian carcinoma at high magnification. The vast majority of the nuclei are heavily stained with anti-pERK1/2 antibodies. In some cells the cytoplasm is also labeled (arrows). Original magnification, x1000.

The latter induces the phosphorylation of MEK, which in turn phosphorylate ERK1/2 that migrates to the nucleus to trigger cell proliferation (39-42). These are classical autocrine and paracrine loops as suggested by us earlier $(27,32,47)$. Our observations that nuclei of the stromal cells adjacent to the tumor are also labeled with $\mathrm{pERK} 1 / 2$ are in line with the notion of a paracrine loop $(27,32,47)$.

In benign serous tumors the nuclei exhibit modest labeling of $\mathrm{pERK} 1 / 2$. In contrast in borderline tumors the labeling is much more intensive. It should be noted that the different appearance of benign mucinous tumors as well as mucinous borderline tumors and serous carcinomas suggest that different subclasses of ovarian cancer may exist at least in serous and mucinous type of cancer $(16,48)$. As for mucinous carcinomas there is some controversy in the literature: early reports claimed for $11-12 \%$ of these carcinomas among total ovarian carcinomas while recent reports claimed for $2-3 \%$ of total mucinous carcinomas (16). Interestingly, in the present work we distin- 

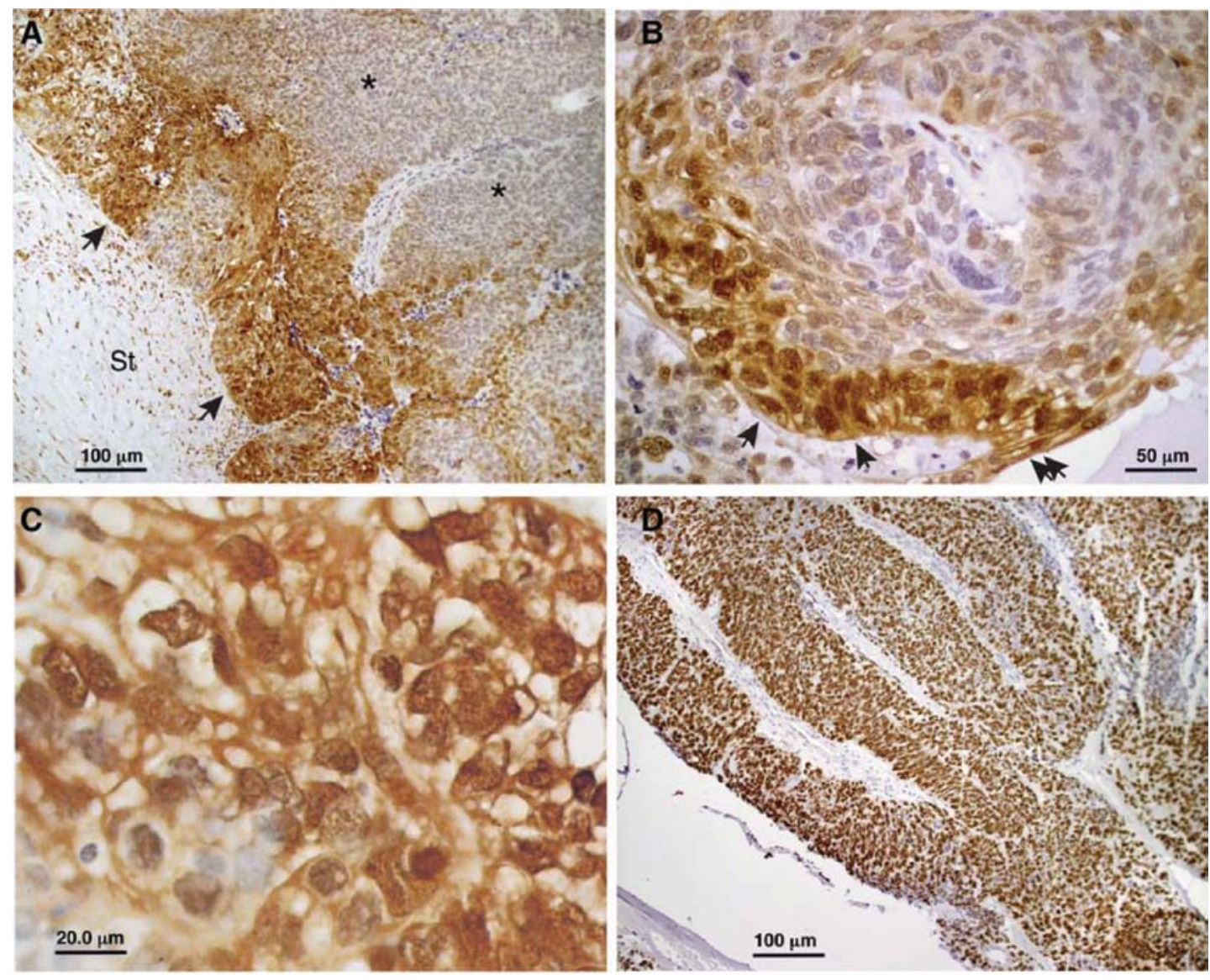

Figure 5. Ovarian endometrioid carcinoma. (A), Note the heavy labeling with anti-pERK1/2 antibodies of cells at the circumference of the tumor (arrows). Other areas remained unstained (asterisks). Clear labeling of nuclei are found in the stroma cell layers (St). Original magnification, $\mathrm{x} 100$. (B), High magnification of endometrioid ovarian carcinoma. Only 3-4 cell layers at the circumference of the tumor are stained for anti-pERK1/2 antibodies (arrows). Nuclei of cells in the stroma are sometime stained (double arrows). Original magnification, $\mathrm{x} 400$. (C), Endometrioid ovarian carcinoma. Most of the nuclei and cytoplasmin in the field are heavily stained with anti-pERK1/2 antibodies. Original magnification, x1000. (D), Ovarian endometrioid carcinoma stained with anti-p53 antibodies. Almost all nuclei of cells in the tumor are positively stained leaving stroma cells unstained. Original magnification, $\mathrm{x} 100$.

guish between benign and borderline mucinous tumors, although they show similar morphology, by the intracellular distribution of $p E R K 1 / 2$. The aggregates of $p E R K 1 / 2$ in the benign and borderline tumors raise the question, what is the mechanism of such aggregations? Probably, this matter could be solved by high-resolution electron microscopy using colloidal gold attached to specific antibodies to pERK1/2. Mucinous benign and borderline tumors should also be analyzed for different biomarkers to see whether functionally there are separated subclasses in mucinous cancer (16).

We also found different appearance of serous borderline tumors and carcinomas. It may well be that this is a reflection of subtypes of this class of ovarian cancer. Adjacent to tumor cells, stromal cell nuclei were often labeled with pERK1/2. This is not surprising since the EGF-like factors produced by the tumor cells can exert their effect both in autocrine as well as in poracrine loops (reviewed in refs, 27,32,47). In endometrioid ovarian cancer only part of the tumor cells, mainly at the circumference of the tumors were labeled with pERK1/2, however, all endometrioid ovarian tumors were labeled with mutated p53. Since mutation of p53 in all tumor cells resemble the advanced state of the cancer (48) it may suggest that there is no necessity for pERK $1 / 2$ to be present in the nuclei beside the growing edges of the tumor. Moreover, it may suggest that
pERK $1 / 2$ is an early marker of ovarian carcinoma which may disappear at least in part upon progression of the cancer associated with the mutation of oncogenes such as p53.

The intense nuclear labeling of pERK1/2 in serous, mucinous and endometrioid carcinomas suggest the important role for $\mathrm{pERK} 1 / 2$ signaling in cell proliferation of ovarian cancer (reviewed in refs. 39-42). As mentioned before, this activation is mediated by interaction of EGF-like factors produced by the cancer cells $(27,32,47)$. Interestingly, high labeling of the carcinoma cells with $\gamma$ sinuclein in all types of carcinomas inspected by us (unpublished data; 49,50) suggest another mechanism of activation of MAPK $(50,51)$ which results in enhancement of cancer cell motility (51) as well as enhancement of drug resistance to chemotherapy, due to inhibition of apoptosis (52). The neoplastic transformation is probably triggered also by other molecular events as mutation of BRCA1, 2, 3, KRAS, mutated p53, Ki67 and others (reviewed in refs. 2,3,17,18,20-22,35), but it seems clear that phosphorylation of ERK1/2 is one of the early events and may assist in the early diagnosis and prognosis of ovarian cancer, which is the most lethal gynecological cancer in women $(1-15,53)$. It was recently demonstrated using proteomics that there is only a slight elevation of pERK $1 / 2$ at the 4 different stages of ovarian carcinomas (53). However, the novelty of our work is the dramatic elevation of pERK $1 / 2$ already in benign 
and borderline tumors compared to normal ovaries. Moreover, immunohistochemical methods could be sometimes more accurate than proteomics, since in immunocytochemistry we inspect individual cells and nuclei, while in proteomics, homogenates of tissues are analyzed, and some residues of normal tissues can blur the results. However, proteomics has a great potential in the analysis of numerous cancer markers simultaneously $(53,54)$. Moreover, it is hoped that a better understanding of the microRNA expression involved in the ovarian cancer may provide new avenues for the detection, diagnosis and therapy of this deadly disease (55).

Recent work claims that the entry of pERK $1 / 2$ to nuclei is restricted in cultures of epithelial cells isolated from the human mammary gland and the ovary (56). However, the age of the women whose epithelial cells were derived, was not indicated. We found in the present work pERK1/2 labeled nuclei and cytoplasm of epithelial cells in normal ovary. This discrepancy may arise from the fact that in the present work we analyzed ovarian tissues obtained from post-menopausal women while in the earlier report (56) cells might have derived from younger women. We clearly observed cytoplasmic and nuclear localization of pERK1/2 in the ovarian epithelial tissues that were taken from post-menopausal women. Moreover, labeled nuclei of epithelial cells with pERK1/2 may indicate their potential to undergo proliferation and transformation $(40,42)$. In addition, labeling with pERK1/2 was evident in the present work in stromal cell nuclei adjacent to the tumor. This may suggest that these cells could have also the potential to undergo transformation. All in all, immunohistochemistry and immunocytochemistry of pERK1/2 seems valuable for the early diagnosis and prognosis of ovarian cancer development. Moreover, the discovery of new subtype of ovarian carcinomas as revealed in the present work may lead to more accurate selection of regiments for the treatment of this disease. In addition, as was exemplified in the present work, that localization of pERK1/2 in mucinous tumors can assist in determining the grade of the tumors even if they show a similar morphology.

\section{Acknowledgements}

We thank Dr Fortune Kohen of the Department of Biological Regulation at The Weizmann Institute of Science for helpful discussions. We also thank Ms. Danielle Sabah-Israel and Ms. Rina Tzoref at the Weizmann Institute of Science for typing the manuscript.

\section{References}

1. Schaner ME, Ross DT, Ciaravino G, Sorlie T, Troyanskaya O, Diehn M, Wang YC, Duran GE, Sikic TL, Caldeira S, Skomedal H, Tu IP, Hernandez-Boussard T, Johnson SW, O'D wyer PJ, Fero MJ, Kristensen GB, Borresen-Dale AL, Hastie T, Tibshirani R, van de Rijn M, Teng NN, Longacre TA, Botstein D, Brown PO and Sikic BI: Gene expression patterns in ovarian carcinomas. Mol Biol Cell 14: 4376-4386, 2003

2. Lee H, Park G, Jung JH, Ahn WS, Lee JM, Kim BK and Kang CS: Diagnostic approach using the expression profiling of the P53 tumor suppressor gene and its related proteins in ovarian epithelial tumors. Int J Gynecol Cancer 15: 453-461, 2005.

3. Singer G, Stöhr R, Cope L, Dehari R, Hartmann A, Cao DF, Wang TL, Kurman RJ and Shih IeM: Patterns of p53 mutations separate ovarian serous borderline tumors and low- and highgrade carcinomas and provide support for a new model of ovarian carcinogenesis: a mutational analysis with immunohistochemical correlation. Am J Surg Pathol 29: 218-224, 2005.
4. Bowen NJ, Walker LD, Matyunina LV, Logani S, Totten KA, Benigno BB and McDonald JF: Gene expression profiling supports the hypothesis that human ovarian surface epithelia are multipotent and capable of serving as ovarian cancer initiating cells. BMC Med Genomics 2: 71, 2009.

5. Vrabie CD, Petrescu A, Waller M and Dina I: Clinical factors and biomarkers in ovarian tumors development. Rom J Morphol Embryol 49: 327-338, 2008.

6. Kobel M, Kalloger SE, Boyd N, McKinney S, Mehl E, Palmer C, Leung S, Bowen NJ, Ionescu DN, Rajput A, Prentice LM, Miller D, Santos J, Swenerton K, Gilks CB and Huntsman D: Ovarian carcinoma subtypes are different diseases: implications for biomarker studies. PLoS Med 5: e232, 2008.

7. Christie M and Oehler MK: Molecular pathology of epithelial ovarian cancer. J Br Menopause Soc 12: 57-63, 2006.

8. Tinelli A, Vergara D, Martignago R, Leo G, Pisanò M and Malvasi A: An outlook on ovarian cancer and borderline ovarian tumors: focus on genomic and proteomic findings. Curr Genomics 10: 240-249, 2009.

9. Köbel M, Kalloger SE, Santos JL, Huntsman DG, Gilks CB and Swenerton KD: Tumor type and substage predict survival in stage I and II ovarian carcinoma: insights and implications. Gynecol Oncol 116: 50-56, 2010.

10. Gubbels JA, Claussen N, Kapur AK, Connor JP and Patankar MS: The detection, treatment, and biology of epithelial ovarian cancer. J Ovarian Res 3: 8, 2010.

11. Kurman RJ and Shih Ie M: The origin and pathogenesis of epithelial ovarian cancer: a proposed unifying theory. Am J Surg Pathol 34: 433-443, 2010.

12. Yurkovetsky Z, Skates S, Lomakin A, Nolen B, Pulsipher T, Modugno F, Marks J, Godwin A, Gorelik E, Jacobs I, Menon U, Lu K, Badgwell D, Bast RC Jr and Lokshin AE: Development of a multimarker assay for early detection of ovarian cancer. J Clin Oncol 28: 2159-2166, 2010.

13. Tuma RS: Origin of ovarian cancer may have implications for screening. J Natl Cancer Inst 102: 11-13, 2010.

14. Pothuri B, Leitao MM, Levine DA, Viale A, Olshen AB, Arroyo C, Bogomolniy F, Olvera N, Lin O, Soslow RA, Robson ME, Offit K, Barakat RR and Boyd J: Genetic analysis of the early natural history of epithelial ovarian carcinoma. PLoS One 5: e10358, 2010.

15. Mackay HJ, Brady MF, Oza AM, Reuss A, Pujade-Lauraine E, Swart AM, Siddiqui N, Colombo N, Bookman MA, Pfisterer J and Du Bois A: Gynecologic Cancer InterGroup. Prognostic relevance of uncommon ovarian histology in women with stage III/IV epithelial ovarian cancer. Int J Gynecol Cancer 20: 945-952, 2010.

16. Frumovitz M, Schmeler KM, Malpica A, Sood AK and Gershenson DM: Unmasking the complexities of mucinous ovarian carcinoma. Gynecol Oncol 117: 491-496, 2010.

17. O'Neill CJ,Deavers MT, Malpica A, Foster H and McCluggage WG: An immunohistochemical comparison between low-grade and high-grade ovarian serous carcinomas: significantly higher expression of p53, MIB1, BCL2, HER-2/neu, and C KIT in high-grade neoplasms. Am J Surg Pathol 29: 1034-1041, 2005.

18. Shi HR and Zhang RT: Expression and significance of P53, P21WAF1 and CDK1 proteins in epithelial ovarian cancer. Ai Zheng (in Chinese) 28: 882-885, 2009.

19. Nielsen JS, Jakobsen E, Hølund B, Bertelsen K and Jakobsen A: Prognostic significance of p53, Her-2, and EGFR overexpression in borderline and epithelial ovarian cancer. Int J Gynecol Cancer 14: 1086-1096, 2004.

20. Bar JK, Słomska I, Rabczyńki J, Noga L and Gryboś M: Expression of p53 protein phosphorylated at serine and serine 392 in malignant and benign ovarian neoplasms: correlation with clinicopathological parameters of tumors. Int J Gynecol Cancer 19: 1322-1328, 2009.

21. Nakayama N, Nakayama K, Yeasmin S, Ishibashi M, Katagiri A, Iida K, Fukumoto M and Miyazaki K: KRAS or BRAF mutation status is a useful predictor of sensitivity to MEK inhibition in ovarian cancer. Br J Cancer 99: 2020-2028, 2008.

22. Feng Q, Deftereos G, Hawes SE, Stern JE, Willner JB, Swisher EM, Xi L, Drescher C, Urban N and Kiviat N: DNA hypermethylation, Her-2/neu overexpression and p53 mutations in ovarian carcinoma. Gynecol Oncol 111: 320-329, 2008.

23. Roh MH, Yassin Y, Miron A, Mehra KK, Mehrad M, Monte NM, Mutter GL, Nucci MR, Ning G, McKeon FD, Hirsch MS, Wa X and Crum CP: High-grade fimbrial-ovarian carcinomas are unified by altered p53, PTEN and PAX2 expression. Mod Pathol 23: $1316-1324,2010$. 
24. Maniccia AW, Lewis C, Begum N, Xu J, Cui J, Chipitsyna G, Aysola K, Reddy V, Bhat G, Fujimura Y, Henderson B, Reddy ES and Rao VN: Mitochondrial localization, ELK-1 transcriptional regulation and growth inhibitory functions of BRCA1, BRCA1a, and BRCA1b proteins. J Cell Physiol 219: 634-641, 2009.

25. García-Sáenz JA, Custodio A, Casado A, Vidart JA, Coronado PJ, Martín M, López-Tarruella S, Puente J, Fernández C and Díaz-Rubio E: Platinum-based adjuvant chemotherapy on moderate- and high-risk stage I and II epithelial ovarian cancer patients. Long-term single institution experience and literature review. Clin Transl Oncol 13: 121-132, 2011.

26. Anglesio MS, Carey MS, Köbel M, Mackay H and Huntsman DG: Vancouver Ovarian Clear Cell Symposium Speakers. Clear cell carcinoma of the ovary: A report from the first Ovarian Clear Cell Symposium, June 24th, 2010. Gynecol Oncol, 2011.

27. Ben-Ami I, Freimann S, Armon L, Dantes A, Ron-El R and Amsterdam A: Novel function of ovarian growth factors: combined studies by DNA microarray, biochemical and physiological approaches. Mol Hum Reprod 12: 413-419, 2006.

28. Nilsson EE and Skinner MK: Role of transforming growth factor beta in ovarian surface epithelium biology and ovarian cancer Reprod Biomed Online 5: 254-258, 2002.

29. Tanaka Y, Miyamoto S, Suzuki SO, Oki E, Yagi H, Sonoda K, Yamazaki A, Mizushima H, Maehara Y, Mekada E and Nakano H: Clinical significance of heparin-binding epidermal growth factor-like growth factor and a disintegrin and metalloprotease 17 expression in human ovarian cancer. Clin Cancer Res 11: 4783-4792, 2005.

30. Mutsaers AJ, Francia G, Man S, Lee CR, Ebos JM, Wu Y, Witte L, Berry S, Moore M and Kerbel RS: Dose-dependent increases in circulating TGF-alpha and other EGFR ligands act as pharmacodynamic markers for optimal biological dosing of cetuximab and are tumor independent. Clin Cancer Res 15: 2397-2405, 2009.

31. Maihle NJ, Baron AT, Barrette BA, Boardman CH, Christensen TA, Cora EM, Faupel-Badger JM, Greenwood T, Juneja SC, Laf ky JM, Lee H, Reiter JL and Podratz KC: EGF/ErbB receptor family in ovarian cancer. Cancer Treat Res 107: 247-258, 2002.

32. Freimann S, Ben-Ami I, Hirsh L, Dantes A, Halperin R and Amsterdam A: Drug development for ovarian hyper-stimulation and anti-cancer treatment: blocking of gonadotropin signaling for epiregulin and amphiregulin biosynthesis. Biochem Pharmacol 68: 989-996, 2004

33. Zeren T, Inan S, Seda Vatansever H, Ekerbicer $\mathrm{N}$ and Sayhan S: Significance of tyrosine kinase activity on malign transformation of ovarian tumors: a comparison between EGF-R and TGF alpha. Acta Histochem 110: 256-263, 2008.

34. Ejskjaer K, Sørensen BS, Poulsen SS, Forman A, Nexø E and Mogensen O: Expression of the epidermal growth factor system in endometrioid cancer. Gynecol Oncol 104: 158-167, 2007.

35. Lee JS, Choi YD, Lee JH, Nam JH, Choi C, Lee MC, Park CS, Juhng SW and Min KW: Expression of cyclooxygenase-2 in epithelial ovarian tumors and its relation to vascular endothelial growth factor and p53 expression. Int J Gynecol Cancer 16 (Suppl 1): 247-253, 2006.

36. Ginath S, Menczer J, Friedmann Y, Aingorn H, Aviv A, Tajima K, Dantes A, Glezerman M, Vlodavsky I and Amsterdam A: Expression of heparanase, Mdm2, and erbB2 in ovarian cancer. Int J Oncol 18: 1133-1144, 2001.

37. Kodama J, Shinyo Y, Hashen G, Hongo A, Yoshinouchi M and Hiramatsu Y: Heparanase messenger RNA expression in epithelial ovarian tumor. Int J Mol Med 12: 961-964, 2003.

38. Davidson B, Shafat I, Risberg B, Ilan N, Trope' CG, Vlodavsky I and Reich R: Heparanase expression correlates with poor survival in metastatic ovarian carcinoma. Gynecol Oncol 104: 311-319, 2007.
39. Plotnikov A, Zehorai E, Procaccia S and Seger R: The MAPK cascades: signaling components, nuclear roles and mechanisms of nuclear translocation. Biochim Biophys Acta (In press).

40. Keshet $Y$ and Seger R: The MAP kinase signaling cascades: a system of hundreds of components regulates a diverse array of physiological functions. Methods Mol Biol 661: 3-38, 2010.

41. Chuderland D, Konson A and Seger R: Identification and characterization of a general nuclear translocation signal in signaling proteins. Mol Cell 31: 850-861, 2008.

42. Yao Z and Seger R: The ERK signaling cascade - views from different subcellular compartments. Biofactors 35: 407-416, 2009.

43. Robinson MJ, Stippec SA, Goldsmith E, White MA and Cobb MH: A constitutively active and nuclear form of the MAP kinase ERK2 is sufficient for neurite outgrowth and cell transformation. Curr Biol 8: 1141-1150, 1998.

44. Vicent S, López-Picazo JM, Toledo G, Lozano MD, Torre W, Garcia-Corchón C, Quero C, Soria JC, Martín-Algarra S, Manzano RG and Montuenga LM: ERK1/2 is activated in nonsmall-cell lung cancer and associated with advanced tumours. $\mathrm{Br}$ J Cancer 90: 1047-1052, 2004.

45. Bae JH and Schlessinger J: Asymmetric tyrosine kinase arrangements in activation or autophosphorylation of receptor tyrosine kinases. Mol Cells 29: 443-448, 2010.

46. Zehorai E, Yao Z, Plotnikov A and Seger R: The subcellular localization of MEK and ERK - a novel nuclear translocation signal (NTS) paves a way to the nucleus. Mol Cell Endocrinol 314: 213-220, 2010.

47. Freimann S, Ben-Ami I, Dantes A, Armon L, Ben Ya'cov-Klein A, Ron-El R and Amsterdam A: Differential expression of genes coding for EGF-like factors and ADAMTS1 following gonadotropin stimulation in normal and transformed human granulosa cells. Biochem Biophys Res Commun 333: 935-943, 2005.

48. Vang R, Shih IeM and Kurman RJ: Ovarian low-grade and highgrade serous carcinoma: pathogenesis, clinicopathologic and molecular biologic features, and diagnostic problems. Adv Anat Pathol 16: 267-282, 2009.

49. Liu H, Liu W, Wu Y, Zhou Y, Xue R, Luo C, Wang L, Zhao W, Jiang JD and Liu J: Loss of epigenetic control of synuclein-gamma gene as a molecular indicator of metastasis in a wide range of human cancers. Cancer Res 65: 7635-7643, 2005.

50. Bruening W, Giasson BI, Klein-Szanto AJ,Lee VM, Trojanowski JQ and Godwin AK: Synucleins are expressed in the majority of breast and ovarian carcinomas and in preneoplastic lesions of the ovary. Cancer 88: 2154-2163, 2000.

51. Pan ZZ, Bruening W and Godwin AK: Involvement of RHO GTPases and ERK in synuclein-gamma enhanced cancer cell motility. Int J Oncol 29: 1201-1205, 2006.

52. Pan ZZ, Bruening W, Giasson BI, Lee VM and Godwin AK: Gamma-synuclein promotes cancer cell survival and inhibits stress- and chemotherapy drug-induced apoptosis by modulating MAPK pathways. J Biol Chem 277: 35050-35060, 2002.

53. Wulfkuhle JD, Aquino JA, Calvert VS, Fishman DA, Coukos G, Liotta LA and Petricoin EF III: Signal pathway profiling of ovarian cancer from human tissue specimens using reverse-phase protein microarrays. Proteomics 3: 2085-2090, 2003.

54. Vergara D, Tinelli A, Martignago R, Malvasi A, Chiuri VE and Leo G: Biomolecular pathogenesis of borderline ovarian tumors: focusing target discovery through proteogenomics. Curr Cancer Drug Targets 10: 107-116, 2010.

55. Dahiya N and Morin PJ: MicroRNAs in ovarian carcinomas. Endocr Relat Cancer 17: F77-F89, 2010.

56. Smith ER, Cai KQ, Smedberg JL, Ribeiro MM, Rula ME, Slater C, Godwin AK and Xu XX: Nuclear entry of activated MAPK is restricted in primary ovarian and mammary epithelial cells. PLoS One 5: e9295, 2010. 